Boise State University

ScholarWorks

\title{
A Preliminary Evaluation: Demographic and Clinical Profiles and Changes in Functioning in Children Receiving Psychosocial Rehabilitation
}

Bonnie L. Davis Kenaley

Boise State University

Nathaniel J. Williams

CenterPointe, Inc.

\section{(c) $\oplus \Theta \Theta$}




\title{
A Preliminary Evaluation: Demographic and Clinical Profiles and Changes in Functioning in Children Receiving Psychosocial Rehabilitation
}

\author{
Bonnie L. Davis Kenaley \\ Boise State University \\ Nathaniel J. Williams \\ CenterPointe, Inc.
}

\begin{abstract}
The present study is the first to examine the demographic and clinical profiles at intake of children with emotional disturbances who received Child Psychosocial Rehabilitation (CPSR), a relatively new treatment for children suffering with emotional disturbance(ED). Fifty-three children ranging in age from 4 to 18 years received CPSR from a for-profit outpatient child and adolescent mental health clinic located in southwestern Idaho for a minimum of six months. The children's demographic and clinical profiles were examined. In addition, the relationship between the relative change in psychological, emotional, and behavioral functioning as measured by CAFAS (Hodges, 1989, 1994) and PECFAS (Hodges, 1994) scores and the children's age, gender, ethnicity, current living arrangement, type of mental health diagnosis, and severity of impairment at intake were evaluated. Significant improvement in the children's overall functioning was found after six months of treatment. No significant between-group differences were found for gender, age, ethnicity, living situation, diagnosis, number of diagnoses, and overall impairment at intake.
\end{abstract}

Keywords: child psychosocial rehabilitation, emotional disturbance, gender, ethnicity, age, functioning

\section{Introduction}

\subsection{Background}

In 1996, state of Idaho policy makers initiated Psychosocial Rehabilitation (PSR) in response to a statewide gap in comprehensive services for children with emotional disturbances, a diagnosable mental illness that significantly impairs 1 in 10 youths in the United States (U.S. Department of Health and Human Services, 1999). Originally developed in the 1940s as a treatment for adults with severe and persistent mental illness (Drake, Green, Mueser, \& Goldman, 2003; Hughes \& Weinstein, 2000), PSR has grown into a nationally recognized and widely implemented program with a strong evidence-base (see Jonikas \& Cook, 2000, for a summary) with clearly defined professional competencies (Weinstein, 2000), certification and training programs (Styron, Shaw, McDuffie, \& Hoge, 2005), professional associations (e.g., United States Psychiatric Rehabilitation Association), and major research centers at large universities (e.g., Boston University's Center for Psychiatric Rehabilitation). Based on empowerment and cognitive-behavioral frameworks, adult PSR services are provided in the community to foster an individual's perception of human agency, self-esteem, and mastery, and control over one's environment. The ultimate objective being the individual's development and mastery of social, occupation, leisure, and living skills and to live as independently as possible in the community (Hughes \& Weinstein, 2000).

With limited use by four western states, Child Psychosocial Rehabilitation (CSPR) is a relatively new model for treating children with emotional disturbances (ED). Similar to PSR for adults, CPSR utilizes empowerment and cognitive-behavioral models to improve the child's psychological, emotional, and behavioral functioning within his/her natural environment. Considering the child's level of development, resiliency factors, and environmental resources, CPSR focuses on: (a) establishing a positive working relationship with the child and his or her family; (b) increasing the child's and family's motivation and hope; (c) teaching the child and his or her caregivers a broad range of cognitive and behavioral skills designed to remediate symptoms and improve overall functioning; (d) allowing the child and his or her family to rehearse and master new behaviors or skills; and (e) altering 
NOTICE: This is the author's version of a work accepted for publication by Elsevier. Changes resulting from the publishing process,

including peer review, editing, corrections, structural formatting and other quality control mechanisms, may not be reflected in this

document. Changes may have been made to this work since it was submitted for publication. The definitive version has been published in Children and Youth Services Review. DOI: 10.1016/i.childyouth.2010.09.013

environmental contingencies so that desirable behaviors are reinforced and undesirable behaviors are extinguished (Williams, 2009a). In contrast to residential treatment, CPSR provides modification and rehearsal of the taught skills and behaviors in their natural environment, such as the client's home, school, library, and recreational centers and parks, and promotes the mastery of navigating real-life situations.

\subsection{Child Characteristics and Treatment Outcomes}

While few studies have examined the effectiveness of Child Psychosocial Rehabilitation (CPSR) (Williams, 2009a, 2009b; Williams \& Sherr, 2008), an absence of studies exist that explore the consumer profiles (demographic and clinical) of children receiving CPSR, as well as the impact of these profiles on CPSR outcomes. However, studies investigating other treatment models for children with ED have examined the relationship between the child's demographic (age, gender, ethnicity, living status) and clinical profiles (type and severity of diagnosis) and treatment effects. For example, studies have demonstrated that a child's age at intake influences treatment outcomes in contradictory ways, with some studies showing improvement in cognitive-behavioral treatment response for older youth with behavioral problems (Durlack, Fuhrman, \& Lampman, 1991; Dush, Hirt, \& Schroeder, 1989; Jayson, Wood, Kroll, Fraser, \& Harrington, 1998; Kazdin \& Crowley, 1997), while other studies favored improvement in younger children (Dishion \& Patterson, 1992; Emslie, Mayes, Laptook, \& Batt, 2003; Ruma, Burke, \& Thompson, 1996, Southam-Gerow, Kendall, \& Weersing, 2001). In addition, ambiguous results have been found in studies examining the impact of the child's gender on treatment outcomes (Dalsgaard, Mortensen, Frydenberg, \& Thomsen, 2002; Southam-Gerow et al., 2001; Walrath, Mandell, \& Leaf, 2001). Dalsgaard and colleagues (2002) found girls demonstrated significantly less improvement compared with boys at long-term follow-up after receiving treatment for conduct problems. In contrast, Southam-Gerow and colleagues (2001) found gender was as an insignificant factor in response to cognitive-behavioral treatment in a sample of children and adolescents diagnosed with anxiety. Similarly, Walrath and colleagues (2001) found boys and girls with ED did not differ in their mental health functioning after receiving partnership system of care services. Further support for the insignificant impact of age on treatment support was found in Bickman, Andrade, and Lambert (2002) study of 125 children with ED who received specialty home-based services akin to CPSR.

While children of color have been found to drop out of treatment at higher rates than non-Hispanic White children (Kendall \& Sugarman, 1997; Viale-Val, Rosenthal, Curtiss, \& Marohn, 1984), other studies (Jainchill, De Leon, \& Yagelka, 1997; Southam-Gerow et al., 2001; Roy, Roberts, Vernberg, \& Randal, 2008) have found ethnicity as an insignificant influence in treatment response in children with a variety of mental disorders (e.g., anxiety, substance abuse, serious emotional disorders). For example, Roy, Roberts, Vernberg, and Randal (2008) examined the psychological, emotional, and behavioral functioning in a sample of 70 children with ED who received a community-based Intensive Mental Health Program, revealing that the level of functioning after treatment did not differ by the child's ethnic background.

The family constellation also appears to be influential in predicting children's improvement in mental health status. Children living with biological caretakers are more likely to improve in their mental health status after receiving treatment than children living in homes with a nonbiological caretaker (Kazdin \& Crowley, 1997). Conversely, no significant change in psychological, emotional, and behavioral functioning was found in children who lived in foster care and received a school-based Intensive Mental Health Program compared with children who resided with their biological parents (Jacobs, Roberts, Vernberg, Nyre, Randall, \& Puddy, 2008). Walrath et al. (2001) found children with ED who were placed in foster care due to family violence and severe family dysfunction demonstrated significantly less improvement in their overall functioning compared with children who did not manifest such high risk factors. Likewise, Reyno and McGrath (2006) found fewer behavioral gains subsequent to treatment in children living with families marked with severe and multiple stressors and poor coping compared with children living in higher functioning families.

Numerous studies have found that the child's severity of impairment at intake has significantly impacted his/her response to different mental health treatments, including parent training, multimodal treatment for ADHD, cognitively-based individual psychotherapy for children with conduct problems, and clinic-based psychotherapy for anxiety (Emslie et al., 2003; Kazdin \& Crowley, 1997; Owens et al., 2003; Reyno \& McGrath, 2006; SouthamGerow et al., 2001). Children with fewer symptoms have been found to perform better at the end of treatment compared with children with greater symptomatology. Kazdin and Crowley studied 120 children, ages 7 to 13 years, with a history of aggressive and antisocial behavior. Their findings revealed that the number of symptoms influenced treatment outcomes, with children having fewer symptoms faring better at the end of treatment compared 
NOTICE: This is the author's version of a work accepted for publication by Elsevier. Changes resulting from the publishing process,

including peer review, editing, corrections, structural formatting and other quality control mechanisms, may not be reflected in this

document. Changes may have been made to this work since it was submitted for publication. The definitive version has been published in Children and Youth Services Review. DOI: 10.1016/i.childyouth.2010.09.013

with children having several behavioral symptoms, In contrast, Jacobs et al. (2008) found that child-level variables including history of sexual abuse, presence of internalizing disorders, and co-occurring internalizing and externalizing disorders were related to poorer response to an intensive school-based treatment for children with ED.

\subsection{Research Question}

The dearth of research on CPSR and the present demand for information concerning the profiles of children who benefit from mental health services (Barth \& Jonson-Redi, 2000; Redding, Fried, \& Britner., 2000) necessitates exploration of the demographic and clinical profiles. In addition, current literature reveals disparate findings as to the impact of the child consumer's profiles on treatment outcomes. Therefore, the present study sought to answer the questions, "What are the demographic and clinical characteristics or profiles of children receiving CPSR?” and "Do the demographic and clinical profiles significantly impact the psychological, emotional, and behavioral outcomes of CPSR?”

\section{Methods}

\section{1 Study Participants}

This study used retrospective data from fifty-three children, ages 4 to 18 years, from low-income families, participating in a CPSR program provided by a for-profit outpatient child and adolescent mental health clinic located in southwestern Idaho between January 2004 and February 2007. The institution review boards at the mental health clinic and Boise State University approved the study. Children were referred to the CPSR program through a variety of sources, including primary care physicians, school officials, Idaho Department of Health and Welfare staff, parent and caregiver referrals, juvenile justice professionals, and service coordinators. According to Idaho Administrative Code 16.03.09.701-16.03.10.199.206 (Idaho Department Health and Welfare), children receiving CPSR must have a valid diagnosis of ED as measured by total Child and Adolescent Functional Assessment Scale (CAFAS; Hodges, 2000) or Preschool and Early Childhood Functional Assessment Scale (PECFAS; Hodges, 1994) score of 80 or higher, with a score of 20 on at least one of the following CAFAS or PECFAS subscales: Moods/Emotions, SelfHarm, or Thinking. In addition, all children in the study had one or more psychiatric diagnoses according to the Diagnostic and Statistical Manual of Mental Disorders ( $4^{\text {th }}$ ed., text revision; American Psychiatric Association, 2000). Diagnoses were assigned by community practitioners (psychiatrists and nurse practitioners) on the basis of their professional judgment during the course of regular clinical services.

\subsection{Child Psychosocial Rehabilitation}

In Idaho, CPSR is a publicly-funded program paid for by Medicaid dollars. The state contracts with private forprofit providers who deliver CPSR services according to statewide administrative regulations (Idaho Administrative Code, Dept Health and Welfare, Code number 16.03.09.701 - 16.03.10.199, 2006; Idaho Department of Health and Welfare, 2007) and oversees CPSR programs by requiring prior authorization of all CPSR services. CPSR programs are required to undergo a credentialing process every three years and are responsible to conduct CPSR assessments (to determine eligibility and service needs), create PSR task plans, and provide CPSR services. Regional Medicaid oversight bodies review CPSR assessments and CPSR service plans to determine whether clients meet inclusion criteria and whether the number of intervention hours requested are appropriate for the client's needs. Services are typically authorized in one-year blocks, with an average enrollment of 13 months.

Utilizing an empowerment and cognitive-behavioral frameworks, CPSR is based on a biopsychosocial model of psychopathology, which considers the derivation of functional impairments stemming from the presence and interaction of biological, emotional, and social etiology (U.S. Department of Health and Human Services, 1999; Williams, 2009b). Biological factors such as biochemistry, biophysical growth and development, as well as biophysical hazards are considered as influential in the manifestation of psychopathology. Psychological features (e.g., cognitive development and information processing, communication skills, perception of self and others, emotional regulation, problem-solving abilities and adaptive/maladaptive behaviors) and barriers for well-being in the child's social sphere (impaired family systems, inappropriate boundaries, lack of social supports, institutions, and resources and maladaptive environments) may cultivate the presence of psychological, emotional, and behavioral symptomatology. In addition, the interaction between biological, psychological, and social domains may further complicate the presentation of psychopathology.

Clients access PSR services by obtaining a referral from their primary care physician to receive mental health services at the agency. If the referral suggests the child is appropriate for CPSR services, a Master-level clinician (licensed psychologist, licensed master social worker, licensed clinical social worker, certified recreational therapist) 
NOTICE: This is the author's version of a work accepted for publication by Elsevier. Changes resulting from the publishing process,

including peer review, editing, corrections, structural formatting and other quality control mechanisms, may not be reflected in this

document. Changes may have been made to this work since it was submitted for publication. The definitive version has been published in Children and Youth Services Review. DOI: 10.1016/i.childyouth.2010.09.013

conducts an in-depth biopsychosocial assessment and administers the CAFSA/PECFAS during face-to-face interview with the child's parent(s) or caregiver(s). All clinicians complete the CAFAS interrater reliability training and successfully passed the interrater reliability test in accordance with CAFAS guidelines (Hodges, 2003). In concert with the parent(s) and clinician, a task or service plan is developed which outlines the treatment goals and strategies. All documentation is forwarded to Idaho State Department of Health and Welfare's Mental Health Authorities (MHA) for review of the child's acceptance into CPSR treatment.

Upon approval by MHA, the child commences treatment and is assigned a bachelor-level CPSR Specialist. Each CPSR Specialist receives an intensive 12-hour orientation and training covering the topics of CPSR theoretical underpinnings, treatment strategies, child and adolescent development, mental disorders, and documentation procedures. In addition, a one-month mentorship allows the newly-hired CPRS Specialist to shadow and observe an experienced specialist in the field. Weekly supervision by master-level clinicians is provided to each specialist to provide education and support, improve clinical knowledge and skills (e.g., intervention strategies/techniques, child protective issues and policies, family dynamics and relationships, client-worker alliance development), promote socialization to the field of mental health and assist in the development of professional identity (CenterPointe Behavioral and Mental Healthcare, Inc., 2007). In an effort to maintain the highest standards of clinical practice, CPSR Specialists are required to obtain 20 hours of continuing education per year.

CPSR Specialists provide each child with six to eight hours of skill and behavioral modification training per week, with a focus on improving emotional and behavioral managements, relationship building, daily living skills such as hygiene and grooming, and coping strategies to minimize symptoms of mental illness (e.g., mood swings, depression, anxiety, and self-harming behaviors) (CenterPointe Behavioral and Mental Healthcare, Inc., 2007). Children typically receive 6 to 8 hours of individual face-to-face intervention per week with the CPSR Specialist in various venues depending upon the child's psychological, emotional, and behavioral needs. In addition, the specialist spends 1 to 2 hours per week in the child's home to teach the child and family members skills to manage the child's symptoms of mental illness or improve his/her functioning in different domains (school, social, home/family, education/vocation, basic living skills, or community). Skill training is provided through modeling skills, verbal instruction, role-playing skills, prompting use of skills in the community, praising and reinforcing the child for use of the skills, experiential education, sports, crafts, worksheets, lists of rules and consequence with the family, or creating other system to reinforce positive behaviors.

\subsection{Data Collection and Measures}

Information regarding the child's demographic (age, gender, ethnicity, and current living arrangement) and clinical profile was obtained by the agency's master-level clinician during the child's initial assessment and enrollment in the CPSR program. Considering the cognitive and behavioral developmental differences between age groups and their impact on implementing CPSR interventions, the variable of age was collapsed into two school-anchored age categories - prekindergarten thru elementary and middle school through high school. Due to the lack of diversity within the population area, ethnicity was dichotomized into two categories: (a) non-Hispanic white and (b) Other (Hispanic/Latino, African American, Native American and other). The child's current living arrangement at intake was categorized as: (a) living with a biological or adoptive parent(s) or (b) living with a foster or kinship caregiver (biological or non-biological caregiver other than biological/adoptive parent).

Indicators for the child's clinical profile at intake included internalizing and externalizing behaviors and the number of mental health diagnoses). In addition, the severity of the child's psychological, emotional, and behavioral impairment at intake was measured by the number of Child Adolescent Functional Assessment Scale (CAFAS; Hodges, 1989, 1994) or Preschool and Early Childhood Functional Assessment Scale (PECFAS; Hodges, 1994) subscales having scores in the severe range. Children between the ages of 7 to 18 years were evaluated using the CAFAS, whereas children ages 4 to 6 years were assessed using the PECFAS. Both scales assess the domains of School (i.e., ability to function satisfactorily in a group education environment), Home (i.e., extent to which a child observes reasonable rules and performs age-appropriate tasks), Community (i.e., respect for the rights of others and their property and conformity to laws; delinquent acts), Behavior toward Others (i.e., appropriateness of youths' daily behavior), Moods/Emotions (i.e., modulation of youth's emotional life, anxiety and depression), Self-Harm (i.e., extent to which the youth can cope without resorting to self-harmful behavior or verbalizations) and Thinking (i.e., ability of the child to use rational thought processes) (Hodges, Xue, \& Wontring, 2004). The scores for each subscale range from 0 to $30(0=$ no impairment, $10=$ mild impairment, $20=$ moderate impairment, and $30=$ severe impairment) (Hodges, 1994). As recommended by Hodges et al., the severity of the child's impairment at intake was 
NOTICE: This is the author's version of a work accepted for publication by Elsevier. Changes resulting from the publishing process,

including peer review, editing, corrections, structural formatting and other quality control mechanisms, may not be reflected in this

document. Changes may have been made to this work since it was submitted for publication. The definitive version has been published in Children and Youth Services Review. DOI: 10.1016/i.childyouth.2010.09.013

determined by the number of the CAFAS or PECFAS subscale scores within the severe impairment range (subscale score $=30$ ). In addition to the above scales, the CAFAS measures substance use, whereas the PECFAS does not. To ensure consistency across the CAFAS and PECFAS scale scores, the CAFAS substance abuse subscale scores were not included in the analysis.

The CAFAS has been found to demonstrate good inter-rater reliability in a sample of lay raters, psychology graduate students, and frontline social service and juvenile court workers. Pearson correlations for the total scores range from .92 to .96 (Hodges \& Wong, 1996). Fair to good inter-rater reliability was found for the subscales of role performance or delinquent acts within the contexts of school, home, and community (.79 -.90), Behavior Toward Others/Self (.83 - .93) and Moods/Emotions (.74 - .94) (Hodges \& Wong). Good reliability was found for all samples on the total scale scores, whereas the correlation coefficients were the lowest for the undergraduate ratings (high .70s) and highest for the frontline workers (low to high .90s) (Hodges \& Wong). Good construct and concurrent validity was demonstrated after examining the relationship of the CAFAS with the Children's Global Assessment Scale (CGAS; Shaffer, Gould, Brasic, Ambronsini, Fisher, Bird, \& Aluwahlia, 1983), the parent report of the Child Behavior Checklist (Achenbach, 1991), and the Youth Self-Report (YSR; Achenbach \& Edelbrock, 1983) (Hodges \& Wong, 1996).

Similar to the CAFAS, the PECFAS has proven reliability and validity. Using a sample of 30 preschool-aged children enrolled in a large Head Start program and their parents, Murphy et al. (1999) evaluated the instrument's psychometric properties. Interrater reliability for the total PECFAS score was high $(r=.90)$ and the internal consistency of the five subscales revealed an alpha of .86.

The child's response to treatment or overall psychological, emotional, and behavioral functioning was measured using the summed CAFAS or PECFAS subscale scores, resulting in a total score. Aggregate domain scores provide a total score that ranges from 0 to 240 . Total scores from 0 to 10 indicate minimal to no impairment, whereas scores between 20 and 40 represent mild impairment. Scores between 50 and 90 indicate moderate overall impairment and scores of 100 to 130 indicate marked impairment. CAFAS or PECFAS scores of 140 or above indicate severe impairment (Hodges, 1989, 1994).

CAFAS ratings were completed during the course of the child's treatment with initial CAFAS/PECFAS ratings obtained at intake followed by a rating at eight months as a means of evaluating their progress in the program. At each measurement period, the CPSR Specialist evaluated the child's progress from data obtained during semistructured interviews with the child's parent(s)/caregiver(s) based on the child's individualized service plan. Using the data obtained during these interviews, CAFAS or PECFAS scores were then determined by the master's level clinician and CPSR Specialist.

\subsection{Analyses}

SPSS version 17.0 was used to run all statistical analyses (SPSS, 2007). Univariate analyses were completed to describe the demographic and clinical profiles of the children who utilized CPSR. Using histograms, boxplots, and frequency tables, the continuous variables of age and CAFAS/PECFAS subscale and total score were examined for distribution and the absence for outliers. In addition to demographic variables, the mean CAFAS/PECFAS subscale and total scores and standard deviations are presented in Table 1. Independent samples $t$-tests were performed to determine the difference in total CAFAS/PECFAS scores on the characteristics of gender, school-age, ethnicity, living status, mental health diagnosis category, the number of diagnoses, or the number of subscales having scores in the severe range. Using a continuous dependent variable of total CAFAS/PECFAS scores, we conducted seven independent general linear model repeated -measures analyses of variance (GLM-RM ANOVAs) to assess the relationship between the change in overall functioning as measured by the total CAFAS/PECFAS scores (dependent variable) over time and the child's demographic and clinical profile at intake (gender, age, ethnicity, current living arrangement, internalizing and externalizing behaviors, number of mental health diagnoses, and the severity of the child's overall psychological, emotional, and behavioral functioning). Bonferroni correction was used to calculate a more conservative $p$-value, due to the multiple analyses conducted, therefore limiting the risk of committing a Type I error. 
NOTICE: This is the author's version of a work accepted for publication by Elsevier. Changes resulting from the publishing process,

including peer review, editing, corrections, structural formatting and other quality control mechanisms, may not be reflected in this

document. Changes may have been made to this work since it was submitted for publication. The definitive version has been published in Children and Youth Services Review. DOI: 10.1016/i.childyouth.2010.09.013

\section{Results}

\subsection{Child's Demographic and Clinical Profiles}

In reviewing the children's characteristics, the mean age was 10.45 years with boys representing approximately $68 \%$ $(\mathrm{N}=36)$ of the sample. See Table 1 for the sample's demographics. [INSERT TABLE I.] The children were equally dispersed between age groups with $49 \%$ of the children in prekindergarten thru elementary school age. No significant differences in the child's age were found between girls and boys. As expected, the majority of the children were non-Hispanic White (81\%). Examination of the "Other" category revealed approximately 15\% of the total sample was represented by Hispanic/Latino children. Less than $2 \%$ of the children were African American with the remaining children representing Native American or biracial ethnicity. The majority of the children $(89 \%, n=47)$ lived with their biological or adopted parent(s).

The children presented with an array of primary mental health diagnoses, including Attention Deficit Hyperactive Disorder (ADHD), Conduct Disorder, Post-traumatic Stress Disorder (PTSD), and anxiety, mood, thought, adjustment, reactive attachment (RAD), and intermittent explosive (IED) disorders. Table 1 presents the sample's clinical profile. Approximately $65 \%$ of the children presented with internalizing mental health disorders. A larger proportion of boys (47\%) were diagnosed with externalizing behaviors such as ADHD, CD, and REI compared with their female counterparts (11.1\%), whereas girls (89\%) were diagnosed with more internalizing mental health diagnoses. The three most common primary diagnoses were ADHD (26.4\%), PSTD (18.9\%), and Mood Disorders (15.1\%), whereas Thought Disorders (1.9\%) and RAD/IED (1.9\%) were the least common diagnoses given. Less than half of the children had more than one mental health diagnosis.

Univariate analysis of the total CAFAS/PECFAS scores at intake revealed a normal distribution with scores ranging from 80 to 170 with a mean of 112 (SD = 25.11), indicating marked overall psychological, emotional, and behavioral impairment. See Table 1 for a summary of the CAFAS/PECFAS scores. Overall, the children exhibited minimal or mild impairment at intake in the domains of community $(\mathrm{M}=6.60, \mathrm{SD}=8.54)$, self-harm $(\mathrm{M}=9.61$, SD $=11.76)$, and thinking $(\mathrm{M}=6.60, \mathrm{SD}=9.19)$. The low self-harm and thinking scales were expected as children with severe psychosis or self-harming behaviors are declined enrollment in CPSR and utilize more intensive inpatient services. Overall, the children demonstrated moderate impairment in the domains of home $(\mathrm{M}=23.55, \mathrm{SD} 7.10)$ and school $(M=23.58, S D=7.10)$. In addition, the domain scores for behaviors toward others $(M=21.89, S D 7.61)$ and mood and emotions $(\mathrm{M}=22.09, \mathrm{SD}=4.98)$ indicate "moderate" impairment in externalizing and internalizing behaviors. Upon closer examination, almost half of the children experienced marked difficulty in observing rules at home (47\%), functioning in a group setting at school (43\%) and behaving toward others in a respectful and appropriate manner (40\%), whereas less than $2 \%$ of the children demonstrated severe functioning in the areas of community and thinking.

\subsection{Changes in Functioning}

Independent samples $t$-tests were performed to determine the difference in CAFAS/PECFAS scores on the characteristics of gender, school-age, ethnicity, living status, mental health diagnosis category, the number of diagnoses, or the number of subscales having scores in the severe range. No significant differences emerged except for the child's school age. Middle or high school age children scored significantly higher on the total CAFAS/PECFAS compared with children in prekindergarten and elementary school $(t(53)=2.04, \quad p=.047$ (2tailed), suggesting that preadolescents and adolescents present at intake with more difficulty in their overall psychological, emotional, and behavioral functioning than their younger counterparts.

Analysis of repeated measures revealed that the children's overall functioning appreciably improved between baseline and eight months of treatment as indicated by a 40 point decrease in the total CAFAS/PECFAS mean scores $(M=71.70, S D=3.27)$. This change represents a significant overall improvement from exhibiting "marked" impairment to "moderate" impairment, $F(1,52)=65.75$, p .000). The total CAFAS/PECFAS scores remained unchanged in $9 \%$ of the children $(n=5)$ and the scores for one child $(2 \%)$ revealed an increase score from 100 to 110. Table II. presents the baseline CAFAS/PECFAS score for each characteristic and the mean change in the CAFAS/PECFAS scores over eight months. [INSERT TABLE II.]No significant between-group differences were found for gender, school-age, ethnicity, living situation, diagnosis, number of diagnoses, and number of subscales having a score in the severe range. 
NOTICE: This is the author's version of a work accepted for publication by Elsevier. Changes resulting from the publishing process,

including peer review, editing, corrections, structural formatting and other quality control mechanisms, may not be reflected in this

document. Changes may have been made to this work since it was submitted for publication. The definitive version has been published in Children and Youth Services Review. DOI: 10.1016/i.childyouth.2010.09.013

The interaction terms of each model were evaluated to assess the differential improvement as a function of the demographic characteristics (gender, school-age, ethnicity, and living arrangement) and clinical profile (internalizing and externalizing behaviors, number of diagnoses, and severity of impairment). No significant interaction effects were found between the total CAFAS/PECFAS scores and the children's demographic variables. However, a marginal interaction was seen for school-age on the total CAFAS/PECFAS scores, $F(1,51)=3.99$, $p$.051. Insignificant findings were revealed for the interaction effect for the children's clinical profile at intake (internalizing and externalizing behaviors, number of diagnoses, and severity of functioning) on the total CAFAS/PECFAS scores. These findings indicate that categories for each demographic characteristic and clinical profile had statistically equivalent rates of improved functioning over the eight months of treatment.

\section{Discussion and Limitations}

CPSR services appear to be equivalently used by boys and girls across all age groups. Utilization of CPSR is overrepresented by non-Hispanic Whites, which was expected as minorities represent less than 6\% of Idaho's population (U.S. Census Bureau, 2008). Considering the lack of access to and under utilization of mental health programs by minorities (U.S. Department of Health and Human Services, 2009), these findings suggest the need to examine accessibility and availability of mental health resources for minority populations in Idaho. Most of the children lived with their biological or adoptive parent(s) and experienced significant impairment in interpersonal family functioning. This finding emphasizes the need for thorough family assessment and to provide family-centered treatments focused on enhancing family relations and individual and family functionality. The study revealed that children receiving CPRS present with a variety of challenges in their internalizing and externalizing behaviors that transcends the venues of home and school. As a community and home-based intervention, CPSR focuses on ameliorating these challenges by building partnerships between the child, parents, teachers, and community agencies.

The findings of the present study substantiate previous research which suggests that the child's demographic characteristics, such as gender, age, and ethnicity, are not associated with treatment responses (Anderson et al., 2008; Bickman et al., 2002; Dalsgaard et al., 2002; Rosenblatt \& Furlong, 1998; Southam-Gerow et al., 2001; Walrath et al, 2001). Prior research (Jacobs et al., 2008) has revealed that the presence of internalizing disorders were associated with poorer response to treatment in children with ED. In addition, previous studies have found externalizing behaviors are more resistant to psychosocial treatments (Hussey \& Guo, 2005). In contrast, the present study demonstrated an equivalent change in functioning across a variety of clinical presentations, including the number of diagnoses, the severity of the mental health functioning, and the presence of externalizing or internalizing mental health diagnoses. These findings suggest CPSR offers an effective individualized treatment modality in a least-restrictive setting for emotionally disordered children with diverse backgrounds and clinical presentations.

The present study appears to be the first attempt to examine the characteristics of child consumers of CPSR and the influence of demographic characteristics and clinical profile on overall psychological, emotional, and behavioral functioning in children receiving CPSR, a relatively new model for treating ED. Although the study has important implications for practice and future research, it is challenged with limitations. First, the study used retrospective data from a child behavioral health agency that initiated CPRS approximately five years ago, resulting in a small nonprobability sample. In addition to the limited generalizability of the study's findings, the propensity for Type II errors must also be considered as the non-significant results may be due to insufficient power resulting from the small sample size.

Master-level clinicians were trained and certified to administer the CAFAS/PECFAS scales with the parents at the initial assessment. Subsequent, CAFAS/PECFAS scores were administered by the clinicians with the CPSR Specialists who are trained in the CAFAS/PECFAS scores but not certified. The disparity in level of proficiency in using the scales may have impacted the outcomes scores. Reliability of the outcomes may be improved through certification of specialists as well as using teacher ratings. In addition, substance use subscale scores (limited to middle and high school age children) were not included in the total scores for the older youth which may have affected the severity of impairment. However, prior analysis of these scores revealed no or minimal impairment in the adolescents' functioning due to the use of substances. Other contextual factors such as referral source, history and type of prior treatment modality (counseling, pharmacological, both counseling and pharmacological) were not considered. 
NOTICE: This is the author's version of a work accepted for publication by Elsevier. Changes resulting from the publishing process, including peer review, editing, corrections, structural formatting and other quality control mechanisms, may not be reflected in this

document. Changes may have been made to this work since it was submitted for publication. The definitive version has been published in Children and Youth Services Review. DOI: 10.1016/i.childyouth.2010.09.013

While the focus of the present study was limited to the impact of demographic and clinical profiles on the outcomes of CPSR, examination of specific components of CPSR using a component analysis approach in a group or singlesubject design study would be helpful in enhancing this model in treating children with ED. For example, the individual one-on-one interaction between the CPSR and child, as well as the implementation of treatment strategies in a natural setting (recreational venues) versus more structure settings (school) may be influential in improving the child's overall functioning. CPSR Specialist and the child's parent(s) or caregiver(s) meet weekly to discuss the child's progress and to review interventions. During such meetings, the CPSR Specialist may identify factors of the child-parent relationship or the functionality of the parent or caregiver that would impair the child's progress toward positive outcomes. Exploration of this topic may support funding of assessing the functionality of the family system and the coordination of services for all family members.

Using retrospective data of children receiving CPSR, the study's design precluded the opportunity to observe for treatment integrity on behalf of the CPSR Specialists. This raises the possibility of the specialists having implemented the treatment in various forms tailored to their knowledge base and past experiences and impacting the effectiveness and outcomes of the CPSR intervention. Continued investigation including assessment of treatment fidelity would be helpful in substantiating the effectiveness of CPSR and improving treatment protocols.

Further research with larger sample sizes and probability samples are warranted to generalize the findings of who can and will benefit from CPRS. Collaboration of contracted agencies providing CPRS to children with ED would be helpful to further identify the type and background of children enrolled in CPRS and the effectiveness of CPRS in reducing ED symptomatology. The study found that a small number of children experience none or little improvement in their symptomatology. Therefore, it is imperative that future studies focus on the child's strengths and risk factors that affect the effectiveness of CPRS.

Despite the limitations, the present study's findings indicate that children with severe impairment and various demographic and clinical profiles may benefit in their overall functioning while receiving CPSR, a relatively new treatment model for treating ED. As a home and community-based intervention model, CPSR seeks to maintain the client integration with family, friends, and the community and utilizes the support and feedback from the child's parents, teachers, and other mental/physical health care providers. An understanding of the client-level factors that may impact CPSR outcome is important as policymakers and practitioners seek to refine the intervention and allocate services in the most treatment- and cost-efficient manner. 
NOTICE: This is the author's version of a work accepted for publication by Elsevier. Changes resulting from the publishing process,

including peer review, editing, corrections, structural formatting and other quality control mechanisms, may not be reflected in this

document. Changes may have been made to this work since it was submitted for publication. The definitive version has been published in Children and Youth Services Review. DOI: 10.1016/i.childyouth.2010.09.013

\section{References}

Achenbach, T. (1991). Manual checklist/4-18 and 1991 profile. Burlington, VT: University of Vermont, Department of Psychiatry.

Achenbach, T. M. \& Edelbrock, C. (1983). Manual for the Child Behavior Checklist and Revised Child Behavior Profile. Burlington, VT: University of Vermont, Department of Psychiatry.

American Psychiatric Association. (2000). Diagnostic and statistical manual of mental disorders ( $4^{\text {th }}$ ed., text revised). Washington, DC: Author.

Anderson, J. A., Wright, E. R., Kelley, K., \& Kooreman, H. (2008). Patterns of clinical functioning over time for young people served in a system of care. Journal of Emotional and Behavioral Disorders, 16, 90-104.

Barth, R. P. \& Jonson-Reid, M. (2000). Outcomes after child welfare services: Implications for design and performance measures. Child and Youth Services Review, 22, 763-787.

Bickman, L., Andrade, A. R., \& Lambert, E. W. (2002). Dose response in child and adolescent mental health services. Mental Health Services Research, 4, 57-70.

CenterPointe Behavioral and Mental Healthcare, Inc. (2007). Policies and Procedures for Psychosocial Rehabilitation Training Manual. Unpublished manuscript.

Dalsgaard, S., Mortensen, P. B., Frydenberg, M., \& Thomsen, P. H. (2002). Conduct problems, gender and adult psychiatric outcome of children with attention-deficit hyperactivity disorder. British Journal of Psychiatry, 181, 416-421.

Dishion, T. J., \& Patterson, G. R. (1992). Age effects in parent training outcome. Behavior Therapy, 23, 719-729. 
Drake, R.E., Green, A.I., Mueser, K.T., \& Goldman, H.H. (2003). The history of community mental health treatment and rehabilitation for persons with severe mental illness. Community Mental Health Journal, 39, 427-440.

Durlak, J. A., Fuhrman, T., \& Lampman, C. (1991). Effectiveness of cognitive-behavior therapy for maladapting children: A meta-analysis. Psychological Bulletin, 110, 204-214.

Dush, D. M., Hirt, M. L., \& Schroeder, J. E. (1989). Self-statement modification in the treatment of child behavior disorders: A meta-analysis. Psychological Bulletin, 106, 97-106.

Emslie, G. J., Mayes, T. L., Laptook, R. S., \& Batt, M. (2003). Predictors of response to treatment in children and adolescents with mood disorders. Psychiatric Clinics of North America, 26, 435-456.

Hodges, K. (1989; 1994 Revised). Child and Adolescent Functional Assessment Scale. Ypsilanti, MI: Easter Michigan University, Department of Psychology.

Hodges, K. (1994). The Preschool and Early Childhood Functional Assessment Scale. Ypsilanti, MI: Eastern Michigan University.

Hodges, K. (2000). The Child and Adolescent Functional Assessment Scale ( ${ }^{\text {nd }}$ Rev.). Ypsilanti: Eastern Michigan University.

Hodges, K. (2003). CAFAS Manual for Training Coordinators, Clinical Administrators, and Data Managers (2 ${ }^{\text {nd }}$ ed.). Ypsilanti: Eastern Michigan University.

Hodges, K. \& Wong, M. M. (1996). Psychometric characteristics of a multidimensional measure to assess impairment: The Child and Adolescent Functional Assessment Scale. Journal of Abnormal Child Psychology, 5, 445-467.

Hodges, K., Xue, Y., \& Wotring, J. (2004). Use of the CAFAS to evaluate outcomes for youths with severe emotional disturbance served by public mental health. Journal of Child and 
NOTICE: This is the author's version of a work accepted for publication by Elsevier. Changes resulting from the publishing process,

including peer review, editing, corrections, structural formatting and other quality control mechanisms, may not be reflected in this

document. Changes may have been made to this work since it was submitted for publication. The definitive version has been published in Children and Youth Services Review. DOI: 10.1016/i.childyouth.2010.09.013

Family Studies, 13, 325-339.

Hughes, R. \& Weinstein, D. (2000). Best Practices in Psychosocial Rehabilitation. Columbia, MD: International Association of Psychosocial Rehabilitation Services.

Hussey, D. l. \& Guo, S. (2005). Characteristics and Trajectories of Treatment Foster Care Youth. Child Welfare, 84(4), 485-506.

Idaho Department of Health and Welfare. (2007). Idaho Administrative Code 16.03.09.70116.03.10.199.206. Unpublished raw data obtained through public records request.

Jacobs, A. K., Roberts, M. C., Vernberg, E. M., Nyre, J. E., Randall, C. J., \& Puddy, R. W. (2008). Factors related to outcome in a school-based intensive mental health program: An examination of nonresponders. Journal of Child and Family Studies, 17, 219-231.

Jainchill, N., De Leon, G., \& Yagelka, J. (1997). Ethnic differences in psychiatric disorders among adolescent substance abusers in treatment. Journal of Psychopathology and Behavioral Assessment, 19, 133-148.

Jayson, D., Wood, A., Kroll, L., Fraser, J., \& Harrington, R. (1998). Which depressed patients respond to cognitive-behavioral treatment? Journal of the American Academy of Child and Adolescent Psychiatry, 37, 35-39.

Jonikas, J., \& Cook, J. (2000). Research in psychosocial rehabilitation. In R. Hughes \& D. Weinstein (Eds.), Best Practices in Psychosocial Rehabilitation. International Association of Psychosocial Rehabilitation Services: Columbia, Maryland.

Kazdin, A. E., \& Crowley, M. J. (1997). Moderators of treatment outcome in cognitively based treatment of antisocial children. Cognitive Therapy and Research, 21, 185-207.

Kendall, P. C. \& Sugarman, A. (1997). Attrition in the treatment of childhood anxiety disorders. Journal of Consulting and Clinical Psychology, 65, 883-888. 
Murphy, J. M., Pagano, M. E., Ramirez, A., Anaya, Y., Nowlin, C., \& Jellinek, M. S. (1999). Validation of the Preschool and Early Childhood Functional Assessment Scale (PECFAS). Journal of Child and Family Studies, 8, 343-356.

Owens, E. B., Hinshaw, S. P., Kraemer, H. C., Arnold, L. E., Abikoff, H. B., Cantwell, D. P., et al. (2003). Which treatments for whom for ADHD? Moderators of treatment response in the MTA. Journal of Consulting and Clinical Psychology, 71, 540-552.

Redding, R., Fried, C., \& Britner, P. (2000). Predictors of placement outcomes in treatment foster care: Implications for foster parent selection and service delivery, Journal of Child and Family Studies, 9(4), pp. 425-447.

Reyno, S. M., \& McGrath, P. J. (2006). Predictors of parent training efficacy for child externalizing behavior problems - a meta-analytic review. Journal of Child Psychology and Psychiatry, 47, 99-111.

Rosenblatt, J. A. \& Furlong, J. J. (1998). Outcomes in a System of Care for Youths with Emotional and Behavioral Disorders: An Examination of Differential Change Across Clinical Profiles. Journal of Child and Family Studies, 7 (2), 217. 232.

Roy, K. M., Roberts, M. C., Vernberg, E. M., \& Randal, C. J. (2008). Measuring Treatment Outcome for Children with Serious Emotional disturbances: Discriminant Validity and Clinical Significance of Child an Adolescent Functioning Assessment Scale. Journal of Child Family Studies, 17, 232-240.

Ruma, P. R., Burke, R. V., \& Thompson, R. W. (1996). Group parent training: Is it effective for children of all ages? Behavior Therapy, 27, 159-169. 
Shaffer, D., Gould, M. S., Brasic, J., Ambronsini, P., Fisher, P., Bird, H., \& Aluwahlia, S. (1983).

A Children’s Global Assessment Scale (CGAS). Archives of General Psychiatry, 40, 1228-1231.

Southam-Gerow, M. A., Kendall, P. C., \& Weersing, V. R. (2001). Examining outcome variability: Correlates of treatment response in a child and adolescent anxiety clinic. Journal of Clinical Child Psychology, 30, 422-436.

SPSS, (2007). SPSS Version 16.0. Chicago, IL: SPSS, Incorporated.

Styron, T. H., Shaw, M., McDuffie, E., \& Hoge, M. A. (2005). Curriculum resources for training direct care providers in public sector mental health. Administration and Policy in Mental Health, 32, 633-649.

U.S. Census Bureau. (2009). The 2009 Statistical Abstract: The National Data Book. Retrieved from http://www.census.gov/compendia/statab/2009edition.html

U.S. Department of Health and Human Services. (1999). Mental health: A report of the Surgeon General. Rockville, MD: U.S. Department of Health and Human Services, Substance Abuse and Mental Health Administration.

U. S. Department of Health and Human Services. (2009). Mental health: A report of the Surgeon General. Rockville, MD: U. S. Department of Health and Human Services.

Viale-Val, G., Rosenthal, R. H., Curtiss, G. M., \& Marohn, R. C. (1984). Dropout from adolescent psychotherapy: A preliminary study. Journal of the American Academy of Child Psychiatry, 23, 562-568.

Walrath, C. M., Mandell, D. S., \& Leaf, P. J. (2001). Responses of children with different intake profiles to mental health treatment. Psychiatric Services, 52, 196-201.

Weinstein, D. (2000). Practitioner competencies. In R. Hughes \& D. Weinstein (Eds.), Best 
NOTICE: This is the author's version of a work accepted for publication by Elsevier. Changes resulting from the publishing process,

including peer review, editing, corrections, structural formatting and other quality control mechanisms, may not be reflected in this

document. Changes may have been made to this work since it was submitted for publication. The definitive version has been published in Children and Youth Services Review. DOI: 10.1016/i.childyouth.2010.09.013

Practices in Psychosocial Rehabilitation. International Association of Psychosocial Rehabilitation Services: Columbia, Maryland.

Williams, N. J. (2009a). Preliminary evaluation of Children’s Psychosocial Rehabilitation for youth with serious emotional disturbance. Research on Social Work Practice, 19, 5-18.

William, N. J. (2009b). Dose-effect of children's psychosocial rehabilitation on the daily functioning of youth with serious emotional disturbance. Child and Youth Care Forum, 38, 273-286.

Williams, N. J., \& Sherr, M. E. (2008). Longitudinal outcomes for youth with serious emotional disturbance during two years of Children's Psychosocial Rehabilitation. Advances in Social Work, 9, 114-129. 
NOTICE: This is the author's version of a work accepted for publication by Elsevier. Changes resulting from the publishing process, including peer review, editing, corrections, structural formatting and other quality control mechanisms, may not be reflected in this document. Changes may have been made to this work since it was submitted for publication. The definitive version has been published in Children and Youth Services Review. DOI: 10.1016/j.childyouth.2010.09.013

Table 1: Demographic and clinical profiles of children with emotional disturbance at intake $(N=53)$.

\begin{tabular}{|c|c|c|c|}
\hline \multicolumn{4}{|l|}{ Demographics } \\
\hline & & M & SD \\
\hline \multirow{2}{*}{\multicolumn{2}{|c|}{ Age (years) }} & 10.45 & 4.0 \\
\hline & & $\%$ & $n$ \\
\hline \multicolumn{2}{|l|}{ School-anchored age (Prekindergarten thru elementary) } & 49.1 & 26 \\
\hline \multicolumn{2}{|l|}{ Male } & 67.9 & 36 \\
\hline \multicolumn{2}{|l|}{ Ethnicity (non-Hispanic White) } & 81.1 & 43 \\
\hline \multicolumn{2}{|l|}{ Living with biological/adoptive parents(s) } & 88.7 & 47 \\
\hline \multicolumn{4}{|l|}{ Clinical profile } \\
\hline \multicolumn{2}{|l|}{ Internalizing and externalizing behaviors } & $\%$ & $n$ \\
\hline \multicolumn{4}{|l|}{ Internalizing } \\
\hline \multicolumn{2}{|l|}{ Post-traumatic stress disorder } & 64.2 & 29 \\
\hline \multicolumn{2}{|l|}{ Mood disorder (depressive, bipolar disorder) } & 18.9 & 10 \\
\hline \multicolumn{2}{|l|}{ Anxiety disorder } & 15.1 & 8 \\
\hline \multicolumn{2}{|l|}{ Thought disorder } & 5.7 & 3 \\
\hline \multicolumn{2}{|l|}{ Adjustment disorder } & 1.9 & 1 \\
\hline \multicolumn{2}{|l|}{ Developmental disorder } & 9.4 & 5 \\
\hline \multicolumn{2}{|l|}{ Externalizing } & 35.8 & 19 \\
\hline \multicolumn{2}{|l|}{ Attention deficit hyperactivity disorder } & 26.4 & 14 \\
\hline \multicolumn{2}{|l|}{ Conduct disorder } & 7.5 & 4 \\
\hline \multicolumn{2}{|l|}{ Reactive attachment/intermittent explosive disorders } & 1.9 & 1 \\
\hline & & M & SD \\
\hline \multicolumn{2}{|l|}{ Number of mental health diagnoses } & 1.65 & .83 \\
\hline & $\%$ & $N$ \\
\hline \multicolumn{2}{|l|}{1 diagnosis } & 58.5 & 31 \\
\hline \multicolumn{2}{|l|}{2 diagnoses } & 18.9 & 10 \\
\hline \multicolumn{2}{|l|}{3 or more diagnoses } & 22.6 & 12 \\
\hline \multicolumn{2}{|l|}{ Total CAFAS/PECFAS scores at intake } & 111.89 & 25.11 \\
\hline \multicolumn{2}{|l|}{ Total CAFAS/PECFAS scores at 8 months } & 71.70 & 3.27 \\
\hline $\begin{array}{l}\text { Severity of the child's psychological, emotional, and behavioral impairment } \\
\text { (CAFAS/PECFAS subscale scores }\end{array}$ & $\begin{array}{l}\text { No/mild } \\
(\% / n)\end{array}$ & $\begin{array}{l}\text { Moderate } \\
(\% / n)\end{array}$ & $\begin{array}{l}\text { Marked } \\
(\% / n)\end{array}$ \\
\hline Home & $9.4(5)$ & $\begin{array}{l}43.49 \\
(23)\end{array}$ & $47.2(25)$ \\
\hline School & $20.8(11)$ & $35.8(19)$ & $\begin{array}{l}43.4 \\
923)\end{array}$ \\
\hline Community & $79.2(42)$ & $18.9(10)$ & $1.9(1)$ \\
\hline Behavior toward others & $20.8(11)$ & $39.6921)$ & $39.6(21)$ \\
\hline Mood & $3.7(2)$ & $71.7(38)$ & $24.5(13)$ \\
\hline Self-harm & $60.4(32)$ & $26.4(14)$ & $13.2(7)$ \\
\hline Thinking & $73.6(39)$ & $24.5(13)$ & $1.9(1)$ \\
\hline Number of CAFAS/PECFAS subscale scores in severe range & & $\%$ & $n$ \\
\hline 0 subscales & & 62.3 & 33 \\
\hline 1 subscale & & 22.6 & 12 \\
\hline 2 or 3 subscales & & 15.1 & 8 \\
\hline
\end{tabular}


NOTICE: This is the author's version of a work accepted for publication by Elsevier. Changes resulting from the publishing process, including peer review, editing, corrections, structural formatting and other quality control mechanisms, may not be reflected in this document. Changes may have been made to this work since it was submitted for publication. The definitive version has been published in Children and Youth Services Review. DOI: 10.1016/j.childyouth.2010.09.013

Table 2: Change between baseline and eight months CAFAS/PECFAS scores considering demographic and clinical profiles $(\mathrm{N}=53)$.

\begin{tabular}{|l|l|l|}
\hline Demographic & $\begin{array}{l}\text { Baseline mean } \\
\text { score (SD) }\end{array}$ & $\begin{array}{l}\text { Change in mean } \\
\text { scores (SD) }\end{array}$ \\
\hline Gender & & \\
\hline Male & $108.82(28.26)$ & $-28.32(32.10)$ \\
\hline Female & $113.33(23.78)$ & $-45.83(32.63)$ \\
\hline School-anchored age & & \\
\hline Prekindergarten thru elementary & $118.85(24.22)$ & $-50.01(36.06)$ \\
\hline Middle school thru high school & $105.19(24.55)$ & $-20.75(29.5)$ \\
\hline Ethnicity & & \\
\hline Non-Hispanic White & $110.70(25.58)$ & $-37.22(32.72)$ \\
\hline Other (Hispanic, African American, Native American, biracial) $117.00(23.59)$ & $-71.00(33.40)$ \\
\hline Living arrangement & & \\
\hline Biological/adoptive parent/caregiver & $112.13(24.04)$ & $-41.50(32.66)$ \\
\hline Foster/kinship caregiver & $110.00(35.21)$ & $-30.00(35.21)$ \\
\hline \hline Clinical profile & & \\
\hline Diagnosis & & \\
\hline Internalizing & $111.30(25.18)$ & $-38.69(30.87)$ \\
\hline Externalizing & $115.71(26.36)$ & $-40.00(45.77)$ \\
\hline Number of mental health diagnoses & & \\
\hline 1 diagnosis & $107.42(21.13)$ & $-41.29(32.11)$ \\
\hline 2 diagnoses & $123.00(27.51)$ & $-44.00(33.48)$ \\
\hline 3 or 4 diagnoses & $114.17(31.18)$ & $-34.17(34.17)$ \\
\hline Number of CAFAS/PECFAS subscales in severe range & & \\
\hline 0 subscales & $110.00(27.50)$ & $-54.25(24.50)$ \\
\hline 1 subscale & $112.50(20.94)$ & $-27.50(24.31)$ \\
\hline 2 or more subscales & $118.75(21.67)$ & $-1.25(19.82)$ \\
\hline & & \\
\hline
\end{tabular}

